\title{
Developmental Psychology, Infant
}

National Cancer Institute

\section{Source}

National Cancer Institute. Developmental Psychology, Infant. NCI Thesaurus. Code C16730.

Developmental psychology research focusing on the infant period. 